\title{
Event-scale blooms drive enhanced primary productivity at the Subtropical Convergence
}

\author{
J. Llido, ${ }^{1}$ V. Garçon, ${ }^{1}$ J. R. E. Lutjeharms, ${ }^{2}$ and J. Sudre ${ }^{1}$ \\ Received 2 March 2005; revised 20 June 2005; accepted 15 July 2005; published 13 August 2005.
}

[1] Frontal systems in the Southern Ocean are known for their enhanced biological activity, with some tantalising suggestions that this enhancement may be intermittent. We have used frequent satellite ocean colour observations to investigate the Subtropical Convergence south of Africa. We demonstrate that the biological enhancement takes place as episodic chlorophyll bloom events with limited spatial and temporal scales. Most of the events appear in austral spring-summer. Two typical lifetimes, 8-24 and 40-60 days, emerge unambiguously during these seasons. A similar analysis has been carried out on modelled chlorophyll fields to investigate the physical-biogeochemical causes for such events. Strong and swift stratification, alleviating the light limitation on growth of phytoplankton, causes the appearance of a bloom. A mixed layer depth expansion subsequently leads to a rapid disappearance of the simulated event. Phytoplankton horizontal transport, either zonal or meridional, also plays a key role on the lifetime of the bloom events. Citation: Llido, J., V. Garçon, J. R. E. Lutjeharms, and J. Sudre (2005), Event-scale blooms drive enhanced primary productivity at the Subtropical Convergence, Geophys. Res. Lett., 32, L15611, doi:10.1029/2005GL022880.

\section{Introduction}

[2] The Subtropical Convergence is one of the major frontal systems in the world ocean. It is not just simply a biogeographical boundary, but forms a unique biological habitat of its own [Longhurst, 1998]. Although the Subtropical Convergence circles most of the globe, geographically its intensity varies considerably [Belkin and Gordon, 1996]. In the South Atlantic, for instance, it is weak [Smythe-Wright et al., 1998] and ephemeral whereas south of Africa between $10^{\circ}-70^{\circ} \mathrm{E}$ it is enhanced by the juxtaposition of the warm Agulhas Return Current [Lutjeharms and Ansorge, 2001]. The horizontal salinity gradient here can exceed $0.06 \mathrm{psu} / \mathrm{km}$ [Lutjeharms and Ansorge, 2001] and the temperature gradient $0.15^{\circ} \mathrm{C} / \mathrm{km}$ [Lutjeharms and Valentine, 1984]. The subtropical waters to the north of the front are oligotrophic and nutrient-poor with strong vertical stratification. To the south, subantarctic waters are by contrast rich in nutrients - bar silicate - with weak stratification. Satellite remote sensing indicates that - on average - it is a region of intense

\footnotetext{
${ }^{1}$ Laboratoire d'Etudes en Géophysique et Océanographie Spatiales, Centre National de la Recherche Scientifique, Toulouse, France.

${ }^{2}$ Department of Oceanography, University of Cape Town, Rondebosch, South Africa.
}

Copyright 2005 by the American Geophysical Union. 0094-8276/05/2005GL022880 mesoscale turbulence presenting enhanced levels of chlorophyll-a [Weeks and Shillington, 1996] and thus a presumed prime region of carbon drawdown from the atmosphere [Metzl et al., 1999]. Ship crossings have on occasion shown substantial peaks in chlorophyll- $a$ at the front [Allanson et al., 1981], but at other times these peaks are absent [Lutjeharms et al., 1985]. If the normal mode of primary productivity at the front consists of intermittent bloom events, as these observations suggest, this would have substantial implications for the manner in which the frontal ecosystem and potential carbon drawdown function. This part of the front south of Africa is furthermore recognised for its well-developed pelagic community structure [Barange et al., 1998]. All these factors make this part of the front ideal for investigating the processes conducive to enhanced primary productivity and we have therefore focused our investigation here.

[3] The purpose of this work is to investigate if the biological enhancement does consist of sporadic bloom events and, if so, to examine the physical-biogeochemical processes responsible for such events, through a comparative study between remote sensing observations and modelled fields.

\section{Data and Method}

[4] Time series of ocean colour and sea surface temperature for the period October 1997 to December 1998 are used in this study. Chlorophyll- $a$ concentrations were obtained from the weekly SeaWiFS products (level 3, $9 \times$ $9 \mathrm{~km}$, version 4) (available at http://www.oceancolor. gsfc.nasa.gov/REPROCESSING/SeaWiFS/R4/). Sea surface temperatures were acquired from the daily composite products (1/10 degree spatial resolution) that are based on AVHRR (Advanced Very High Resolution Radiometer) observations from the NOAA-14 satellite [May et al., 1998]. The usefulness of both these data sets is constrained by extensive and persistent cloud cover in this region.

[5] To investigate the physical and biological interactions responsible for the appearance and disappearance of bloom events, an N-P-Z-D (dissolved inorganic nutrient, phytoplankton, zooplankton, detritus), nitrogen-based, biological model [Oschlies and Garçon, 1998]-coupled with a threedimensional physical model [Biastoch and Krauss, 1999]is used. It has an eddy-permitting resolution $\left(1 / 3^{\circ}\right)$ in the study region and 29 vertical levels, with level intervals increasing from $15 \mathrm{~m}$ at the surface to $250 \mathrm{~m}$ at depth. It is forced with monthly means of wind stress and short-wave radiation based on NCEP/NCAR reanalysis (available at http://www.cdc.noaa.gov/cdc/reanalysis) for the 19952001 period [Llido et al., 2004]. Initial model conditions 


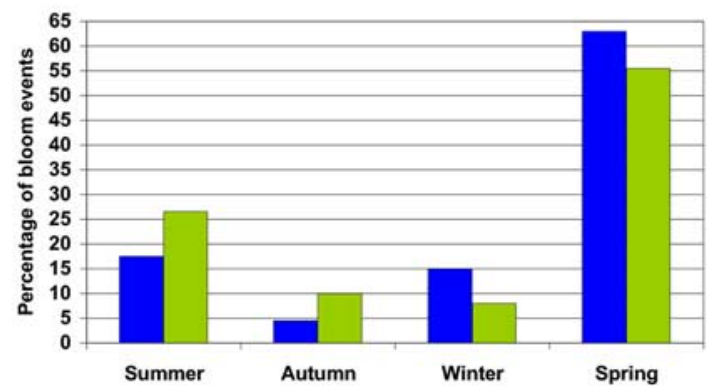

Figure 1. The seasonal distribution of chlorophyll- $a$ bloom events detected during the period October 1997December 1998 between $10^{\circ}-70^{\circ} \mathrm{E}$ and $38.5^{\circ}-43^{\circ} \mathrm{S}$. The green histogram represents the frequency of blooms as percentage garnered from SeaWiFS satellite observations and the blue one that of modelled blooms.

are taken from a stable climatological run [Machu et al., 2005].

\section{Statistical Analysis: Detection and Classification}

[6] Our studied domain extends from $10^{\circ}$ to $70^{\circ} \mathrm{E}$ between $38.5^{\circ}-43^{\circ} \mathrm{S}$, including both the Agulhas Front and the Subtropical Convergence.

[7] Animations of modelled chlorophyll fields every five days and SeaWiFS fields every week have been set up to track possible bloom events during their full lifetime. A detection protocol for such events, based on a threshold concentration, has been established and applied on SeaWiFS and modelled chlorophyll concentrations [Llido, 2004]. The background concentration of chlorophyll- $a$ in the region, as estimated from satellite observations of ocean colour [Weeks and Shillington, 1996] as well as obtained from in situ observations [Read et al., 2000], lies between 0.4-0.6 $\mathrm{mgChl} a / \mathrm{m}^{3}$. A threshold concentration of $0.7 \mathrm{mgChla} / \mathrm{m}^{3}$, as evident in satellite remote sensing, has thus been used to distinguish regions of noteworthy concentrations. At first glance this may seem a low value to be used as criterion for exceptional chlorophyll- $a$ concentrations; in practice regions of localised enrichment identified in this way in remote sensing products are very distinct and conspicuous. Values of $1.0 \mathrm{mgChla} / \mathrm{m}^{3}$ are in fact observed throughout the record, i.e., double that of the background, but these are found only in sporadic bloom events with limited spatial dimensions and lifetimes. Consequently, for each bloom event detected in the selected region, several characteristics (date, central location, maximum chlorophyll concentration, zonal and meridional extensions) have been recorded at each time step of its existence. We then classified the detected bloom events as a function of their lifetime, strength, areal extent, and spatial seasonal distribution.

[8] Most of these events detected from SeaWiFS over the period October 1997-December 1998 (Figure 1) appear in austral spring-summer (82\%); fewest are observed during winter. The most prominent chlorophyll- $a$ enrichment events occur in spring, with mean concentrations of between $0.85-1.05 \mathrm{mgChla} / \mathrm{m}^{3}$. The majority $(64 \%)$ of bloom events have a typical lifetime of only 8-24 days (Figure 2).
However, during spring a secondary duration of 40-60 days is evident (Figure 2). These two characteristic lifetimes appear also in summer (not shown). The spatial extent of these blooms varies considerably, but two distinct surface areas emerge from the analysis. The maximum geographic area is found in spring with a mean areal extent lying between 10,000 and $25,000 \mathrm{~km}^{2}$ in 1997 and between 35,000 and $45,000 \mathrm{~km}^{2}$ in 1998 . The surface area of the blooms occurring during the rest of the calendar year is smaller $\left(<10,000 \mathrm{~km}^{2}\right)$. The preponderance of spring-summer events may be caused by light limitation during the rest of the year. Localised bloom events are observed along the Subtropical Convergence over the full domain of our investigation $\left(10^{\circ} \mathrm{E}-70^{\circ} \mathrm{E}\right)$ during spring-summer. During autumn they are, by contrast, confined to the range $10^{\circ}-$ $30^{\circ} \mathrm{E}$. This latter range coincides with that part of the front where horizontal gradients in temperature and salinity are most reinforced by the adjacent Agulhas Return Current. It is also the frontal region where the most intense mesoscale turbulence occurs [Lutjeharms and Valentine, 1988]. This is suggestive, since it has been shown that localised blooms may be associated with eddies [Park et al., 2002]. There does not seem to be any relationship between the lifetime and the areal extent of bloom events nor between their lifetime and their geographic location. This underscores the very sporadic nature of these events. It has been suggested [Lutjeharms et al., 1985] that enhanced primary production at the Subtropical Convergence - epitomized by higher concentrations of chlorophyll- $a$ - could come about by mixing across the front, thus combining the higher nutrient concentrations of subantarctic waters with greater vertical stratification from the subtropics. This hypothesis, as well as the observed seasonal behaviour of bloom events, can in principle be modelled with a coupled physical-biological model [Llido et al., 2004].

[9] The distribution of simulated chlorophyll fields shows that maximum concentrations also appear as episodic localised blooms in the model. Even if the absolute number of events simulated (114) is less than that observed (263 events) over this period October 1997-December 1998, their seasonal distribution is quite similar. The largest number of bloom events occurs in spring-summer (81\%) and the small-

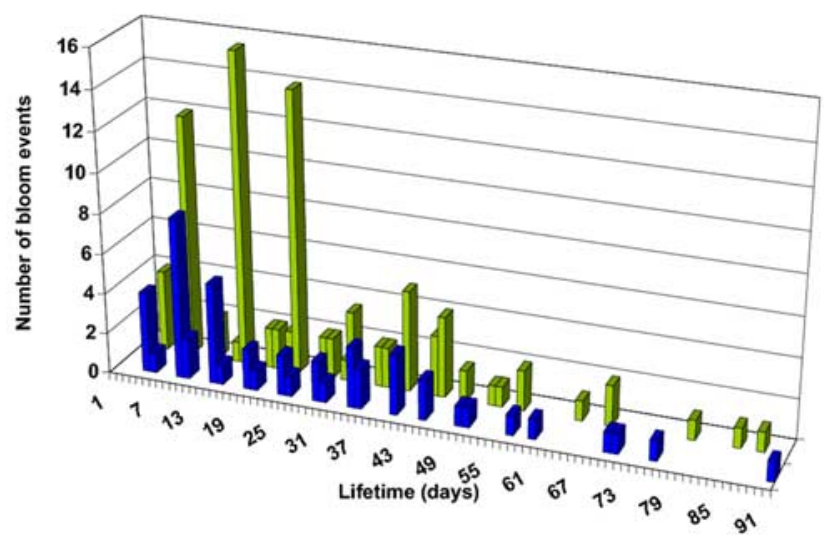

Figure 2. The longevity of chlorophyll- $a$ blooms according to SeaWiFS satellite observations (green) and for those simulated by the model (blue) in both austral springs (October-November-December) 1997 and 1998. 

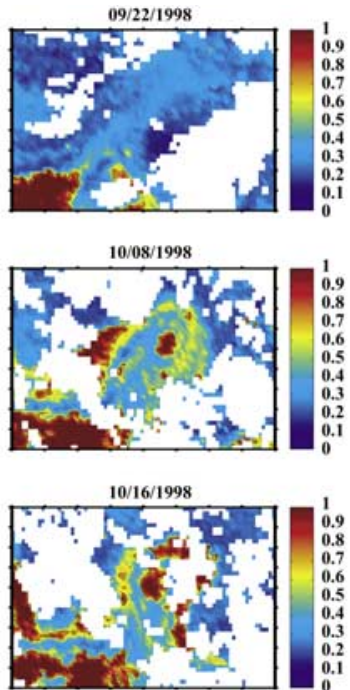

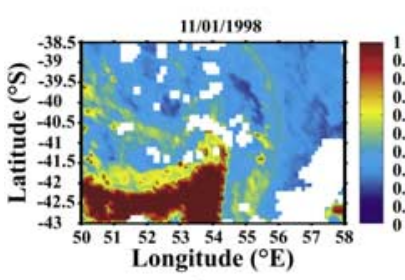

a)
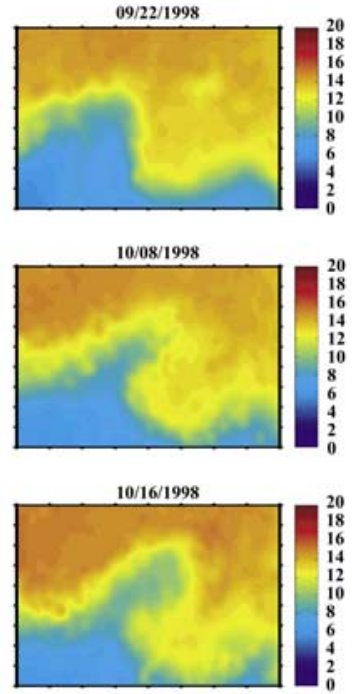

$11 / 01 / 1998$

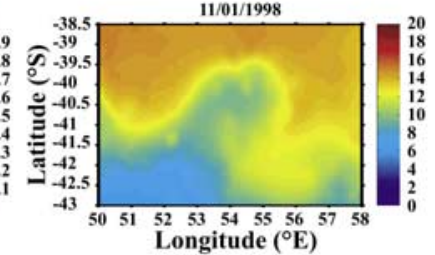

b)

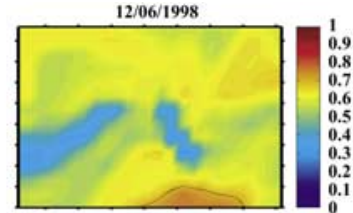

$12 / 16 / 1998$

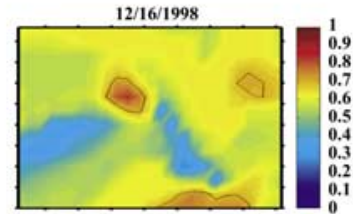

$12 / 26 / 1998$

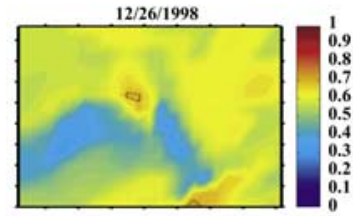

$12 / 31 / 1998$

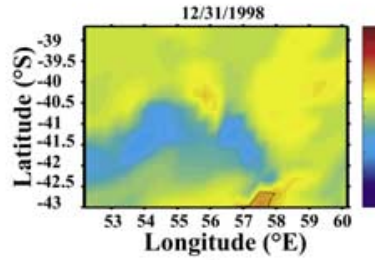

c)

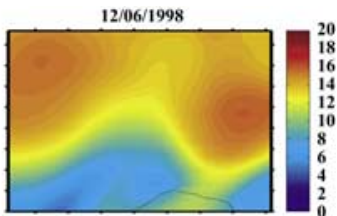

$12 / 16 / 1998$

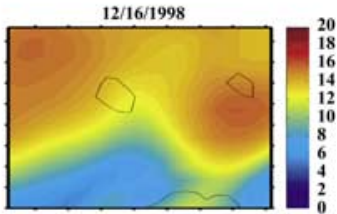

$12 / 26 / 1998$

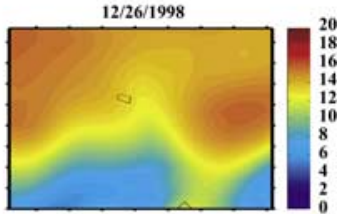

$12 / 31 / 1998$

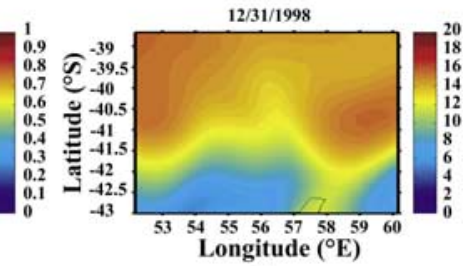

d)

Figure 3. Life history of typical chlorophyll- $a$ blooms at the Subtropical Convergence in satellite observations and from the model simulation. The chronological sequence is from top to bottom. The first column represents the chlorophyll- $a$ concentration $\left(\mathrm{mgChl} a / \mathrm{m}^{3}\right)$ according to SeaWiFS, the second the simultaneous sea surface temperature (SST $\left.{ }^{\circ} \mathrm{C}\right)$ from the NOAA-14 satellite, for the period 22 September to 1 November 1998. The third column gives the chlorophyll- $a$ concentration $\left(\mathrm{mgChl} a / \mathrm{m}^{3}\right)$ and the fourth column the SST both as simulated by the model for the period 6-31 December 1998. Outlines in black circumscribe the location of the bloom core.

est in autumn (Figure 1). The mean chlorophyll- $a$ enrichment over the lifetime of simulated events lies between 0.7 and $0.9 \mathrm{mgChl} / \mathrm{m}^{3}$, with the peak intensities between 1.2 and $1.5 \mathrm{mgChla} / \mathrm{m}^{3}$. The intensity of these modelled enrichments is a slight under-estimate. During spring the number of simulated bloom events with high chlorophyll- $a$ concentrations $\left(>0.9 \mathrm{mgChl} a / \mathrm{m}^{3}\right)$ tends to increase. This is also observed in the ocean colour data. The simulated blooms have two favoured lifetimes during spring (Figure 2). Most have a short lifetime, between 5-15 days, whereas a nonnegligible number have a longer duration of about $30-$ 50 days. These characteristic lifetimes agree substantially with observations. In the model, there is some variability in aerial extent of blooms, but much less so than in the ocean colour observations. In general the modelled blooms remain smaller than $10,000 \mathrm{~km}^{2}$. However, the tendency for blooms to be largest in spring is found both in the model and the ocean colour observations. The geographic distribution of the bloom events along the Subtropical Convergence is quite well reproduced by the model, with blooms found over the full region of interest in spring. In summer-autumn these modelled events are restricted to a zone between $10^{\circ}-30^{\circ} \mathrm{E}$. However for winter, in contrast to the observed bloom events, two specific regions seem to be preferred in the model: one, just south of South Africa $\left(10^{\circ}-30^{\circ} \mathrm{E}\right)$ and the other between $50^{\circ}-70^{\circ} \mathrm{E}$.

[10] The differences between the simulated and the real bloom events may have three main causes. First, we have used smooth, monthly, interannual atmospheric forcing and shortwave radiation to drive the model. This does not include high frequency information. High frequency wind and radiation events may be responsible for the greater number of blooms observed in satellite observations than in the model, for higher chlorophyll- $a$ concentrations in blooms and for bloom events being more extensive than those modelled. Secondly, the horizontal resolution of the model is considerably coarser $(\sim 40 \times 40 \mathrm{~km})$ than that of the ocean colour observations $(9 \times 9 \mathrm{~km})$ and therefore is unable to reproduce the more intense, sub-mesoscale vertical motions that may occur in actual blooms [Flierl and McGillicuddy, 2002]. At last, to be consistent in our analysis, an identical detection threshold has been used for both SeaWiFS and simulated chlorophyll fields. The model slightly underestimates the intensity of the blooms and thus a smaller number of bloom events is achieved since chlorophyll concentrations may remain below the threshold criterion.

[11] Bearing these caveats in mind, we employ the model to investigate the conditions required for bloom events and thus the physico-biogeochemical processes involved.

\section{Event-Scale Blooms Requirements: Underlying Mechanisms}

[12] From this very cloudy region we have selected a substantial number of the clearest visible bloom events and 
compared them to modelled blooms from the same season and with similar duration, location and evolution. We present a representative example in Figure 3. This observed bloom event $\left(\sim 1.20 \mathrm{mgChl} a / \mathrm{m}^{3}\right)$ appeared at $40.4^{\circ} \mathrm{S}-$ $54.8^{\circ} \mathrm{E}$ on 8 October 1998 when subantarctic waters moved close to its location (Figure 3b). The bloom remained stationary, subsequently enlarged (viz. Figure $3 a$ ) and eventually disappeared 24 days later. A comparable bloom was simulated by the model (Figures $3 \mathrm{c}$ and $3 \mathrm{~d}$ ) for 16 December 1998 in a neighbouring region $\left(40.3^{\circ} \mathrm{S}-55.5^{\circ} \mathrm{E}\right)$, also just north of the Subtropical Convergence. During its lifetime of 15 days the modelled bloom, with maximum chlorophyll- $a$ enrichment of $0.84 \mathrm{mgChl} a / \mathrm{m}^{3}$ and primary production that reached $1.2 \mathrm{gC} / \mathrm{m}^{2} /$ day -a $70 \%$ increase in primary production over the surrounding waters-, remained stationary as did the observed bloom (Figure 3a). A strong vertical stratification occurred with a decrease in mixed layer depth of more than 200 meters from 6 November to 16 December. Favourable light conditions and nutrient levels allowed a rapid phytoplankton growth. The local stratification, first initiated by a wind stress relaxation under high solar flux conditions, came from upwelling in the model. November 1998 was marked by a strong downwelling in the region which vanished slowly to be replaced by an upwelling regime in early December that led to a consequent shoaling of the isotherms. Such upwelling may be driven by cyclonic eddies or local Ekman pumping. The extinction of the upwelling mid-December 1998 was gradually replaced by a new downwelling regime, weaker than the previous one but which destroyed the established stratification leading to the disappearance of the simulated bloom. A strong correlation (coefficient of 0.94) exists between the local stratification and the chlorophyll concentration. The enhancement and extinction mechanisms responsible for this particular bloom event are representative for all others investigated.

\section{Summary}

[13] We have studied the presence of chlorophyll- $a$ using frequent satellite views and show that bloom events with limited spatial and temporal scales are indeed the norm along the Subtropical Convergence. Our numerical model fundamentally agrees with this process. We have used this model to investigate the physico-biogeochemical requirements for bloom events and demonstrated that in most cases the limiting factor is intensity of vertical stratification combined with light availability. In the model, other combinations of physical and biological processes can also lead to the demise of blooms. Horizontal advection of phytoplankton, either zonal or meridional, can on occasion maintain the intensity of a bloom event, but leads in some cases to selfshading of phytoplankton and thus inhibition of further growth.

[14] These results have important implications for a better understanding of the functioning of the Subtropical Convergence frontal system. Organisms endemic to this specialised habitat may have to be adapted to a boom-orbust situation. Furthermore, drawdown of inorganic carbon through photosynthesis may occur here as intense pulses, that overwhelm the remineralisation processes and possibly enhance carbon sequestering in the deep ocean. Since the occurrence of optimal conditions for a bloom event are very difficult to predict, the logistical chances of studying a full bloom history in situ are remote, forcing one to rely on even more detailed models.

[15] Acknowledgments. This study was supported through CNES funding to LEGOS. J. Lutjeharms was funded by the University of Cape Town, the South African Antarctic Research Programme and the South African National Research Foundation. Anonymous reviewers are thanked for their constructive comments.

\section{References}

Allanson, B. R., R. C. Hart, and J. R. E. Lutjeharms (1981), Observations on the nutrients, chlorophyll, and primary production of the Southern Ocean south of Africa, S. Afr. J. Antarct. Res., 10/11, 3-14.

Barange, M., E. A. Pakhomov, R. Perissinotto, P. W. Froneman, H. M. Verheye, J. Taunton-Clark, and M. I. Lucas (1998), Pelagic community structure of the subtropical convergence region south of Africa and in the mid-Atlantic Ocean, Deep Sea Res., Part I, 45, 1663-1687.

Belkin, I. M., and A. L. Gordon (1996), Southern Ocean fronts from the Greenwich meridian to Tasmania, J. Geophys. Res., 101, 3675-3696.

Biastoch, A., and W. Krauss (1999), The role of mesoscale eddies in the source regions of the Agulhas Current, J. Phys. Oceanogr., 29, $2303-$ 2317.

Flierl, G. R., and D. J. McGillicuddy (2002), Mesoscale and submesoscale physical-biological interactions, in The Sea, vol. 12 , edited by A. R. Robinson et al., pp. 113-185, John Wiley, Hoboken, N. J.

Llido, J. (2004), Variabilité spatiale et temporelle du système biologique dans la Convergence Subtropicale au sud de l'Afrique, Ph.D. thesis, 303 pp., Univ. Paul Sabatier, Toulouse III, France.

Llido, J., E. Machu, J. Sudre, I. Dadou, and V. Garçon (2004), Variability of the biological front south of Africa from SeaWiFS and a coupled physical-biological model, J. Mar. Res., 62, 595-609.

Longhurst, A. (1998), Ecological Geography of the Sea, 398 pp., Elsevier, New York.

Lutjeharms, J. R. E., and I. Ansorge (2001), The Agulhas Return Current, J. Mar. Syst., 30, 115-138.

Lutjeharms, J. R. E., and H. R. Valentine (1984), Southern Ocean thermal fronts south of Africa, Deep Sea Res., Part A, 31, 1461-1476.

Lutjeharms, J. R. E., and H. R. Valentine (1988), Eddies at the Sub-Tropical Convergence south of Africa, J. Phys. Oceanogr., 18, 761-774.

Lutjeharms, J. R. E., N. M. Walters, and B. R. Allanson (1985), Oceanic frontal systems and biological enhancement, in Antarctic Nutrient Cycles and Food Webs, edited by W. R. Siegfried, P. R. Condy, and R. M. Laws, pp. 11-21, Springer, New York.

Machu, E., A. Biastoch, A. Oschlies, M. Kawamiya, J. R. E. Lutjeharms, and V. Garçon (2005), Phytoplankton distribution in the Agulhas system from a coupled physical-biological model, Deep Sea Res., Part I, 52, $1300-1318$.

May, D. A., M. P. Parmeter, D. S. Olszewski, and B. D. McKenzie (1998), Operational processing of satellite sea surface temperature retrievals at the Naval Oceanographic Office, Bull. Am. Meteorol. Soc., 79, 397-407.

Metzl, N., B. Tilbrook, and A. Poisson (1999), The annual $\mathrm{CCO}_{2}$ cycle and the air-sea $\mathrm{CO}_{2}$ flux in the sub-Antarctic Ocean, Tellus, Ser. B, 51, 849-861.

Oschlies, A., and V. Garçon (1998), Eddy-induced enhancement of primary production in a model of the North Atlantic Ocean, Nature, 394, 266269.

Park, Y.-H., R. T. Pollard, J. F. Read, and V. Leboucher (2002), A quasisynoptic view of the frontal circulation in the Crozet Basin during the Antares-4 cruise, Deep Sea Res., Part II, 49, 1823-1842.

Read, J. F., M. I. Lucas, S. E. Holley, and R. T. Pollard (2000), Phytoplankton, nutrients, and hydrography in the frontal zone between the Southwest Indian Subtropical gyre and the Southern Ocean, Deep Sea Res., Part I, 47, 2341-2368.

Smythe-Wright, D., P. Chapman, C. Duncombe Rae, L. V. Shannon, and S. M. Boswell (1998), Characteristics of the South Atlantic subtropical frontal zone between $15^{\circ} \mathrm{W}$ and $5^{\circ} \mathrm{E}$, Deep Sea Res., Part I, 45, 167-192.

Weeks, S. J., and F. A. Shillington (1996), Phytoplankton pigment distribution and frontal structure in the subtropical convergence region south of Africa, Deep Sea Res., Part I, 43, 739-768.

V. Garçon, J. Llido, and J. Sudre, Laboratoire d'Etudes en Géophysique et Océanographie Spatiales, Centre National de la Recherche Scientifique, 18 Avenue Edouard Belin, 31401 Toulouse Cedex 9, France. (veronique. garcon@cnes.fr)

J. R. E. Lutjeharms, Department of Oceanography, University of Cape Town, 7700 Rondebosch, South Africa. 